\title{
Preexcitation syndrome: experimental study on the electrocardiogram of antegradely conducting accessory pathway
}

\author{
Zhaolong Xu', Renguang Liu' ${ }^{1 *}$, Qinghua Chang ${ }^{1}$ and Changjun Li ${ }^{2}$
}

\begin{abstract}
Background: Preexcitation syndrome is characterized by a dominant delta wave on the baseline electrocardiogram (ECG), resulting from the change in QRS initial vector by the accessory pathway (AP). This study is to explore the effect of ventricular preexcitation on the QRS initial, maximal and terminal vector in an experimental rabbit with preexcitation syndrome induced by programmed electrical stimulation.

Methods: Rabbits $(n=10)$ were randomized for the experimental model of ventricular preexcitation. Sensing and stimulating electrode catheters were placed in the high right atrium and along epicardial surface of atrioventricular groove of the left ventricular anterior wall, respectively. Programmed premature stimulation $S_{2}$ was synchronized with $P$ wave and utilized to stimulate the ventricle. The ECG recorded the electrical activity of the heart. As compared with the QRS complex during sinus rhythm, paced QRS was assessed regarding the initial, maximal and terminal vector. PS $_{2}$ interval and PR interval were also measured and analyzed.
\end{abstract}

Results: Preexcitation was successfully simulated by ventricular pacing in the rabbits, including (1) Complete preexcitation: $\mathrm{PS}_{2}$ interval was less than PR interval; the difference was more than or equal to $47.00 \pm 7.53 \mathrm{~ms}$. (2) Incomplete preexcitation: $\mathrm{PS}_{2}$ interval was less than PR interval; the difference was less than $47.00 \pm 7.53 \mathrm{~ms}$. (3) Incomplete latent preexcitation: $\mathrm{PS}_{2}$ interval was more than or equal to PR interval; the difference was less than or equal to $13.00 \pm 3.50 \mathrm{~ms}$. (4) Complete latent preexcitation: $\mathrm{PS}_{2}$ interval was more than or equal to PR interval; the difference was more than $13.00 \pm 3.50 \mathrm{~ms}$.

Conclusions: The difference in the relative conduction velocity of the atrioventricular node versus the AP pathways determines the degree of preexcitation and different manifestation on ECG. The QRS terminal vector also reflects the ventricle preexcitation, indicating a valuable sign for the diagnosis of atypical or latent preexcitation.

Keywords: Preexcitation syndrome, Atrioventricular accessory pathway, Delta wave, Terminal QRS vector, Electrocardiogram

\section{Background}

Preexcitation syndrome is characterized by the electrocardiographic evidence of short PR interval as well as prolonged QRS containing a delta wave with the secondary ST-T change $[1,2]$. A delta wave indicates that the part of the ventricle which is directly connected to accessory pathway (AP) is depolarized first. Preexcitation syndrome with antegrade AP conduction can be divided

\footnotetext{
*Correspondence: liurenguanglaoshi@126.com

${ }^{1}$ The Cardiovascular Institute of the First Affiliated Hospital of Jinzhou

Medical University, Renmin Street, Jinzhou 121000, Liaoning Province, China Full list of author information is available at the end of the article
}

into overt and latent AP preexcitation based on the electrocardiogram (ECG) [3-5]. In patients with overt AP conduction, the ventricular preexcitation manifested as delta wave on surface ECG. While in patients with latent AP conduction, delta wave is invisible on surface ECG. In our recent study, we compared ECGs before and after ablation in preexcitation syndrome. This study confirmed that preexcitation affected not only the QRS initial vector but also the QRS maximum vector and the QRS terminal vector. Furthermore, we observed that two out of eight cases with latent AP preexcitation had no delta wave but QRS terminal vector changes on

(C) The Author(s). 2018 Open Access This article is distributed under the terms of the Creative Commons Attribution 4.0 International License (http://creativecommons.org/licenses/by/4.0/), which permits unrestricted use, distribution, and 
surface ECG, and we proposed "the incomplete latent preexcitation syndrome" $[6,7]$. In the present study, in order to recognize the influence of the time difference of conduction through accessory pathway and normal pathway on the ECG of the preexcitation, we simulated preexcitation model by electrophysiological technique and changed the antegrade AP conduction, then further explored the effect of antegradely conducting $\mathrm{AP}$ on ECG characteristics.

\section{Methods \\ Material \\ Ethical review}

This study was carried out in strict accordance with the recommendations in the Guide for the Care and Use of Laboratory Animals of the National Institutes of Health. The protocol was approved by the Committee on the Ethics of Animal Experiments of the Jinzhou Medical University.

Ten healthy Japanese White Rabbits, weighing $2.0 \pm$ $0.15 \mathrm{~kg}$, were selected. All of the animals used in this study were housed in the Laboratory Animal Facility of our University.

\section{Preexcitation model}

All the rabbits were anesthetized with urethane $(1.2 \mathrm{~g} / \mathrm{kg})$ for induction. ECG monitor were then pasted to the animals. A left parasternal thoracotomy was performed, and the heart was exposed. The apex of one DAIG bipolar electrode (ST. JUDE company, America) was sutured to the epicardial surface of atrioventricular groove of left ventricular anterior wall, (Equivalent to the ventricular site of left anterior AP), and end of the electrode was kept outside through the cut, as ventricular pacing electrode. The other DIAG lead as atrial sensing electrode was placed at high right atrium via the internal jugular vein. The ends of the two leads were connected to the DF-4 electrophysiological stimulator (Oriental Electronic Company, Suzhou). Ventricular pacing was performed with voltage of twice the threshold of pulse amplitude, $2 \mathrm{~ms}$ of pulse width. We used a model ECG-6511 machine (Shanghai Medical Machine Company, China) to record surface ECG. Electrodes were placed on its arms and legs and right parasternal. The paper speed of ECG was $50 \mathrm{~mm} / \mathrm{s}$ and the gain was $20 \mathrm{~mm} / \mathrm{mV}$. Programmed premature stimulation $S_{2}$ synchronized $\mathrm{P}$ wave positively swept ventricle $\left(\mathrm{PS}_{2}\right.$ interval: $0 \rightarrow \mathrm{PJ}$ interval, step length: $5 \mathrm{~ms}$ ) to record surface ECG of chest lead, and the preexcitation model was simulated. Simultaneously, the ECGs were recorded. Programmed premature stimulation $\mathrm{S}_{2}$ synchronized $\mathrm{P}$ wave positively swept ventricle $\left(\mathrm{PS}_{2}\right.$ interval: $0 \rightarrow \mathrm{PJ}$ interval, step length was $5 \mathrm{~ms})$. The ECGs were recorded and preexcitation was simulated in the rabbit model. Cardioventricular pacing QRS complex by $\mathrm{S}_{2}$ after $\mathrm{T}$ wave was recorded which represents the QRS induced by complete ventricular preexcitation.

\section{Observed value}

(1) The ventricular activation time via normal pathway (sinus PR interval); (2) The initial, maximal and terminal QRS vector through normal pathway (sinus QRS); (3) The ventricular activation time via $\mathrm{AP}\left(\mathrm{PS}_{2}\right.$ interval); (4) The initial, maximal and terminal QRS vector complete through AP ( $\mathrm{S}_{2}$ pacing QRS after $\mathrm{T}$ wave); (5) The initial, maximal and terminal $\mathrm{QRS}$ vector with AP conduction $\left(\mathrm{R}_{2}\right.$ : Ventricular fusion wave formed by $\mathrm{S}_{2}$ and sinus conduction).

\section{The change of $Q R S$ vector}

(1) Initial QRS vector change: the direction or amplitude of initial $20 \mathrm{~ms}$ QRS vector which was different from normal pathway conduction; (2) maximal QRS vector change: the amplitude or direction of maximal QRS amplitude which was different from normal pathway conduction. (3) Terminal QRS vector change: the direction or amplitude of terminal $20 \mathrm{~ms}$ QRS vector which was different from normal pathway conduction.

\section{Assessment of the degree of preexcitation}

(1) complete preexcitation: $R_{2}$ was absolutely equal to QRS complex through AP; (2) incomplete (typical) preexcitation: the initial vector of $R_{2}$ was equal to $Q R S$ complex through AP, but the maximal and terminal vector of QRS alters between normal and AP conduction (ventricular fusion wave); (3) incomplete latent preexcitation: $R_{2}$ was on behalf of ventricular fusion with terminal vector change; (4) complete latent preexcitation: $\mathrm{R}_{2}$ was absolutely equal to QRS complex via normal pathway $\left(S_{2}\right.$ encountered the effective refractory period of the ventricle).

\section{Results}

Preexcitation model by applying electrophysiological technique

Four kinds of different QRS waves were successfully observed on rabbit model of preexcitation, including complete preexcitation, incomplete (typical) preexcitation, incomplete latent preexcitation (terminal QRS vector change) and complete latent preexcitation (Fig. 1).

\section{The effect of the time difference of conduction through AP and normal pathway on the degree of ventricular preexcitation}

The relationships between the degree of ventricular preexcitation and the atrioventricular (AV) conduction time via $\mathrm{A}-\mathrm{V}$ nodal pathway (PR interval), $\mathrm{AV}$ conduction time via $\mathrm{AP}\left(\mathrm{PS}_{2}\right.$ interval), as well as the time difference of $\mathrm{PR}$ and $\mathrm{PS}_{2}$ interval were shown in Table 1 . AP conduction was faster than $\mathrm{AV}$ node conduction $\left(\mathrm{PS}_{2}\right.$ inter$\mathrm{val}<\mathrm{PR}$ interval), and $\mathrm{R}_{2}$ was on behalf of overt preexcitation. When the difference was $\geq 47.00 \pm$ $7.53 \mathrm{~ms}, \mathrm{R}_{2}$ was complete preexcitation, inversely, $\mathrm{R}_{2}$ 


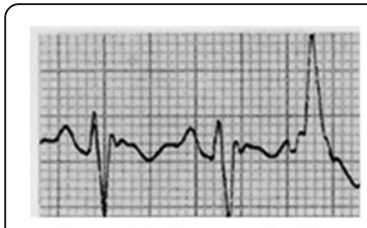

Sinus PR interval: $65 \mathrm{~ms}$

$\longleftarrow$ R3: CVP $\longrightarrow$

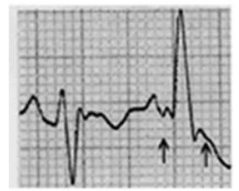

$\mathrm{PS}_{2}: \quad 20 \mathrm{~ms}$

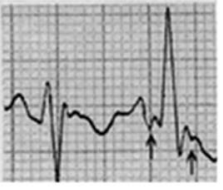

$\mathrm{PS}_{2}: 25 \mathrm{~ms}$

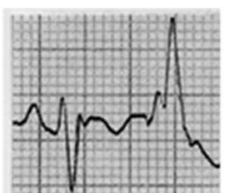

$\mathrm{PS}_{2}: 0 \mathrm{~ms}$

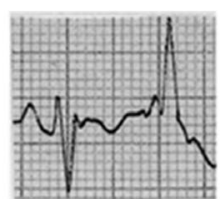

$\mathrm{PS}_{2}: 5 \mathrm{~ms}$

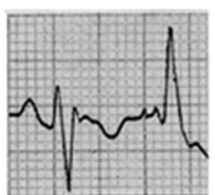

$\mathrm{PS}_{2}: 10 \mathrm{~ms}$

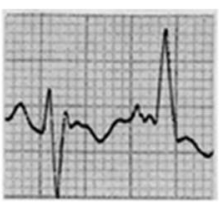

$\mathrm{PS}_{2}: 15 \mathrm{~ms}$

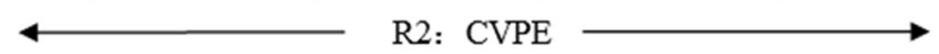

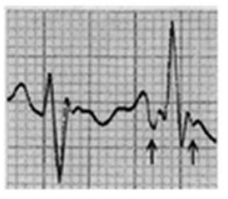

$\mathrm{PS}_{2}: 30 \mathrm{~ms}$

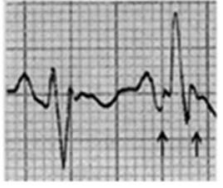

$\mathrm{PS}_{2}: 35 \mathrm{~ms}$

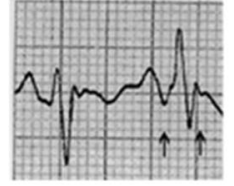

$\mathrm{PS}_{2}: 40 \mathrm{~ms}$

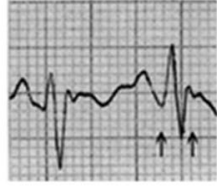

$\mathrm{PS}_{2}: 45 \mathrm{~ms}$

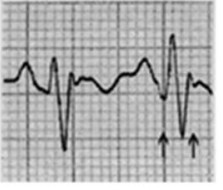

$\mathrm{PS}_{2}: 50 \mathrm{~ms}$ R2: ICVPE

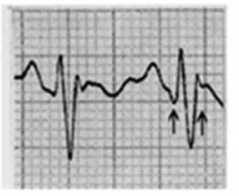

$\mathrm{PS}_{2}: 55 \mathrm{~ms}$

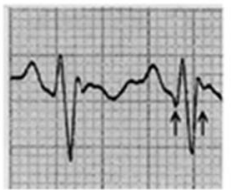

$\mathrm{PS}_{2}: 60 \mathrm{~ms}$

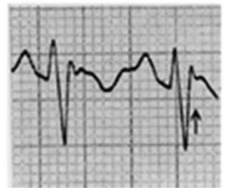

$\mathrm{PS}_{2}: 65 \mathrm{~ms}$

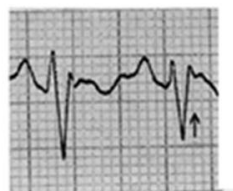

$\mathrm{PS}_{2}: \quad 70 \mathrm{~ms}$

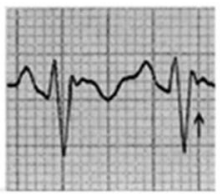

$\mathrm{PS}_{2}: 75 \mathrm{~ms}$

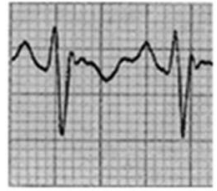

$\mathrm{PS}_{2}: \quad 80 \mathrm{~ms}$

Fig. 1 Four types of QRS complex recorded during ventricular pacing by synchronous pacing of $\mathrm{PS}_{2}$ and $\mathrm{P}$ wave simulating preexcitation of left anterior accessory pathway. Sinus PR interval represents the atrioventricular conduction time via normal pathway; PS $_{2}$ represents atrioventricular conduction time via accessory pathway; R2 represents the different degrees of preexcitation; " " " shows the changes of initial and terminal QRS vectors. CVP: complete ventricular pacing; CVPE: complete ventricular preexcitation; ICVPE: incomplete ventricular preexcitation; ICLPE: incomplete latent preexcitation; CLPE: complete latent preexcitation

was incomplete preexcitation. AP conduction is not faster than $\mathrm{AV}$ node conduction $\left(\mathrm{PS}_{2}\right.$ interval $\geq \mathrm{PR}$ inter$\mathrm{val}$ ), and $\mathrm{R}_{2}$ is latent preexcitation. When the difference was $\leq 13.00 \pm 3.50 \mathrm{~ms}, R_{2}$ was incomplete latent preexcitation, inversely, $R_{2}$ was complete latent preexcitation.

\section{Discussion}

In this study, programmed premature stimulation $\mathrm{S}_{2}$ synchronized P wave positively swept ventricle and ECG of antegradely conducting AP was successfully simulated in the rabbit model including complete preexcitation,

Table 1 The effect of $\mathrm{PS}_{2}$ interval, PR interval and its time difference on QRS complex

\begin{tabular}{|c|c|c|c|c|c|}
\hline \multirow[t]{2}{*}{ Model } & \multirow{2}{*}{$\begin{array}{l}\text { PR interval } \\
\text { a (ms) }\end{array}$} & \multicolumn{4}{|c|}{$\mathrm{PS}_{2}$ interval $\mathrm{b}^{\mathrm{b}}$ time difference between $\mathrm{PS}_{2}$ interval and PR interval (ms) } \\
\hline & & $\begin{array}{l}\text { Complete ventricular } \\
\text { preexcitation }\end{array}$ & $\begin{array}{l}\text { Incomplete ventricular } \\
\text { preexcitation }\end{array}$ & $\begin{array}{l}\text { Incomplete latent } \\
\text { preexcitation }\end{array}$ & $\begin{array}{l}\text { Complete latent } \\
\text { preexcitation }\end{array}$ \\
\hline 1 & 65 & $<25 /<-40$ & $30 \sim 60 /-35 \sim-5$ & $65 \sim 85 / 0 \sim 20$ & $>90 />25$ \\
\hline 2 & 60 & $<15 /<-45$ & $20 \sim 55 /-40 \sim-5$ & $60 \sim 75 / 0 \sim 15$ & $>80 />20$ \\
\hline 3 & 60 & $<25 /<-35$ & $30 \sim 55 /-30 \sim-5$ & $60 \sim 70 / 0 \sim 10$ & $>75 />15$ \\
\hline 4 & 75 & $<15 /<-60$ & $20 \sim 70 /-55 \sim-5$ & $75 \sim 85 / 0 \sim 10$ & $>90 />15$ \\
\hline 5 & 70 & $<5 /<-65$ & $10 \sim 65 /-60 \sim-5$ & $70 \sim 85 / 0 \sim 15$ & $>90 />20$ \\
\hline 6 & 70 & $<20 /<-50$ & $25 \sim 65 /-45 \sim-5$ & $70 \sim 80 / 0 \sim 10$ & $>85 />15$ \\
\hline 7 & 60 & $<20 /<-40$ & $25 \sim 55 /-35 \sim-5$ & $60 \sim 75 / 0 \sim 15$ & $>80 />20$ \\
\hline 8 & 65 & $<15 /<-50$ & $20 \sim 60 /-45 \sim-5$ & $65 \sim 75 / 0 \sim 10$ & $>80 />15$ \\
\hline 9 & 70 & $<20 /<-50$ & $25 \sim 65 /-45 \sim-5$ & $70 \sim 85 / 0 \sim 15$ & $>90 />20$ \\
\hline 10 & 60 & $<15 /<-45$ & $20 \sim 55 /-40 \sim-5$ & $60 \sim 70 / 0 \sim 10$ & $>75 />15$ \\
\hline
\end{tabular}

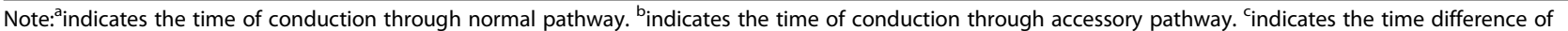
conduction through accessory pathway and normal pathway 
incomplete (typical) preexcitation, incomplete latent preexcitation and complete latent preexcitation. This confirmed that the degree of preexcitation depended on the time difference of conduction through AP and normal pathway.

\section{Feasibility in this study}

The canine model of preexcitation syndrome has been reported in clinical ECG study [8]. In our rabbit model, sensing electrode was placed to high right atrium (sense sinus $\mathrm{P}$ wave) and stimulating electrode was placed to atrioventricular groove of left ventricular anterior wall (simulate preexcitation through a left anterior AP). Programmed premature $\mathrm{S}_{2}$ which synchronized $\mathrm{P}$ wave $\left(\mathrm{PS}_{2}\right.$ interval was equal to the conduction time through $\mathrm{AP}$ ) performed stimulation and built the animal model of preexcitation syndrome in which sinus $\mathrm{P}$ wave can simultaneously conduct through normal pathway and left anterior AP. Various degree of preexcitation (complete preexcitation, incomplete preexcitation, incomplete latent preexcitation and complete latent preexcitation) were obtained during changing $\mathrm{PS}_{2}$ interval, confirming this study was a feasibility study. It can apply to the study of clinical ECG of preexcitation syndrome [9].

\section{The manifestation and influencing factor of antegrade conduction of AP in preexcitation syndrome}

The preexcitation syndrome with AP capable of antegrade conduction could be divided into overt preexcitation and latent preexcitation. In latent preexcitation, the preexcitation is absent on the resting 12-lead ECG, which could be induced by transesophageal atrial pacing. Though there is no delta wave, the prevalence of arrhythmia and the risk of malignancy are same as the overt preexcitation [10-13]. In this study we successfully imitated the ECG manifestation of 4 type preexcitation including complete ventricular preexcitation, incomplete ventricular preexcitation, incomplete latent preexcitation, complete latent preexciation. The finding of this study further confirms that the
ECG manifestation of antegrade conduction of AP depends on the relative time that the atrial impulse is conducted down the AP into ventricle as opposed to the normal pathway. (1) When the AP conduction is faster than the AV node conduction, the overt preexcitation is observed on surface ECG. The degree of preexcitation depends on the how much faster the atrial impulse is conducted down the AP into ventricle as opposed to the normal pathway. If the relative time that the atrial impulse is conducted down the AP into ventricle as opposed to the normal pathway is longer than the time that impulse transmits from the ventricle that is directly connected to AP to the normal pathway (the time of this group is 47.00 $\pm 7.53 \mathrm{~ms}$ ), the atrial impulse can't conduct into ventricle via the normal pathway, resulting in the complete ventricular preexcitation. If the relative time that the atrial impulse is conducted down the AP into ventricle as opposed to the normal pathway is no longer than the time that impulse transmits from the ventricle that is directly connected to AP to the normal pathway, the impulse can conduct into ventricle by the normal pathway and AP forming the monophyletic ventricular fusion, resulting in incomplete ventricular preexcitation (Fig. 2). (2) When the AP conduction is slower than the AV node conduction, the delta wave is absent. If the relative time that the atrial impulse is conducted down the AP into ventricle as opposed to the normal pathway is no longer than the time that impulse transmits from the normal pathway the ventricle that is directly connected to AP (the time of this group is $13.00 \pm 3.50 \mathrm{~ms}$ ), the AP is still able to produce premature ventricular depolarization in the part of the ventricle that is directly connected to the AP forming the ventricular fusion, resulting in the change of terminal QRS vector. During this time the incomplete latent preexcitation could be seen in the ECG (Fig. 3). If the relative time that the atrial impulse is conducted down the AP into ventricle as opposed to the normal pathway is longer or equal to the time that impulse transmits from the

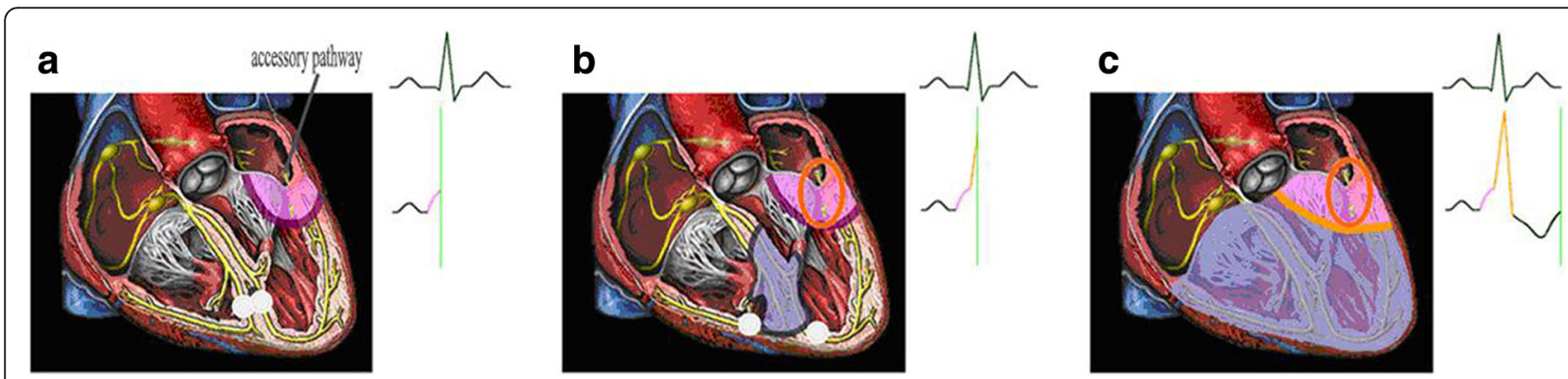

Fig. 2 The delineation of the mechanism of preexcitation syndrome with overt accessory pathway. (a) The activation prematurely depolarizes the ventricle via accessory pathway which is faster than AV node, forming the delta wave. (b) The onset of the normal atrioventricular node conduction is the termination of the delta wave, but the accessory pathway conduction is continuous. (c) The activation simultaneously conducts through the accessory pathway and normal conduction system, fusing into the monophyletic ventricular fusion with delta wave in its initiation and the deformation in its termination 


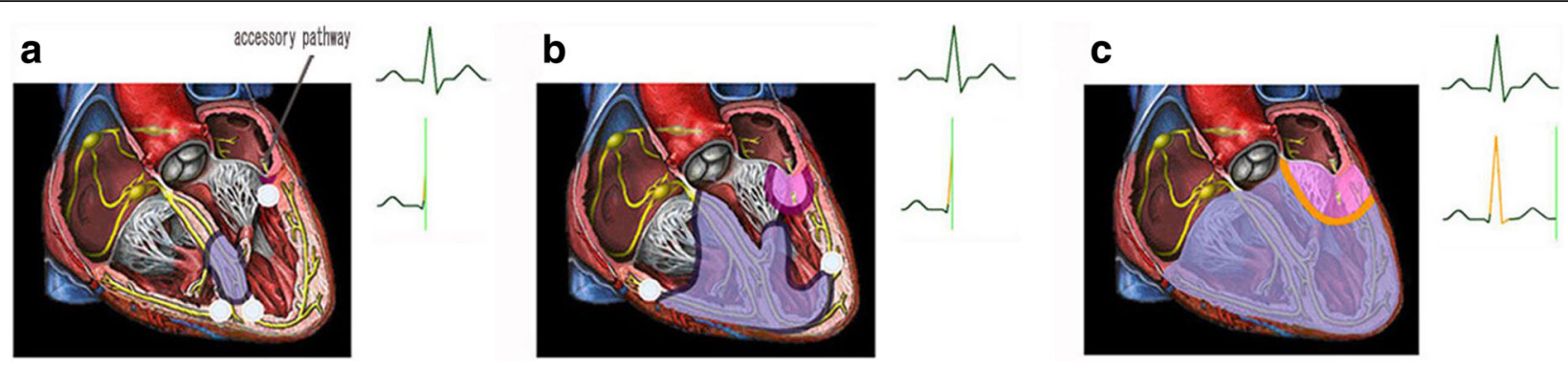

Fig. 3 The delineation of the mechanism of incomplete latent preexcitation. (a) The atrioventricular node conduction is faster than or is equal to accessory pathway conduction, forming normal PR interval without delta wave. (b) The insertion of the ventricle is pre-excited by the activation conducted via the accessory pathway. (c) The activation simultaneously conducted through the accessory pathway and normal conduction system, fusing into the monophyletic ventricular fusion (mainly manifests the change of terminal QRS vector and morphology)

normal pathway the ventricle that is directly connected to AP, the impulse can't conduct into ventricle via AP (encounter the effective refractory period of the ventricle), showing complete latent preexcitation in the ECG.

\section{The clinical significance of different degree of ventricle preexcitation}

In this study the overt preexcitation was divided into complete and incomplete ventricular preexcitation based on the ECG manifestation. The clinical significance is as follows: as to the incomplete ventricular preexcitation which is the classical manifestation of preexcitation syndrome, it is easy to identify; as to the complete ventricular preexcitation, it is easy to misdiagnose resulting from lack of recognition. (1) When AP closes to the pacemaker (atrial premature beats), the intra-atrial conduction time is significantly shortened, resulting in the superimposition of $\mathrm{P}^{\prime}$ wave and QRS complex. During this time the PR interval is indistinguishable, and the premature atrial contraction is often misdiagnosed as premature ventricular contraction [14]. Furthermore, the polarity of initial QRS vector is identical to the delta wave, the finding of premature $\mathrm{P}^{\prime}$ wave is helpful for the diagnosis. (2) When the AV node conduction is obviously slower than AP conduction, such as first or third degree atrioventricular block (AVB) in normal pathway with complete ventricular preexcitation, the AVB in normal pathway is masked which is usually misdiagnosed in clinic [15-17]. During this time, the QRS complex is obviously widened and the PJ interval should be measured. The PJ interval prolongation provides that there is AVB in the normal pathway $[15,16,18]$. It is important for preoperative preparation and postoperative medical malpractice prevention to identify the presence of AVB according to ECG analysis before ablation.

In this study the latent preexcitation was divided into "incomplete latent preexcitation" and "complete latent preexcitation". The clinical significance is as follows: the absence of delta wave is not means that the impulse can't conduct down AP into ventricle. In patients with incomplete latent preexcitation syndrome, the delta wave is absent, but the impulse can conduct into ventricle via AP resulting in the change of terminal QRS vector [6]. The recognition of this new type preexcitation theoretically updates the recognition of delta wave. Meanwhile, it is helpful for the diagnosis of preexcitation syndrome mainly with a change of terminal QRS vector and the analysis of curative effect of bypass ablation [19-21]. However, it is not easy to observe the change of terminal QRS vector which could be found in comparison to the ECG during atrioventricular reentrant tachycardia or after ablation.

The multiple leads were not synchronously detected, and it had a certain influence on the accurate analysis of the terminal QRS vector. It will be helpful to analyze the relationship between the terminal QRS vector and the AP location if the multiple leads can be simulated. Besides, in previous study [22-24], researchers have observed the effects of ionic channel, gene, oxidative stress and inflammation on arrhythmias, and ventricular depolarization. Therefore, further studies are needed to assess whether these factors have influences on the electrocardiogram of antegradely conducting accessory pathway in future.

\section{Conclusions}

(1) The ECG manifestation of antegrade conduction of AP depends on the relative time that the atrial impulse is conducted down the AP into ventricle as opposed to the normal pathway. The ECG includes manifest complete ventricular preexcitation, incomplete ventricular preexcitation, incomplete latent preexcitation, complete latent preexcitation according to the degree of preexcitation.

(2) In the preexcitation syndrome, the presence of a delta wave indicates that AV accessory pathway conduction is faster than AV node conduction; the antegrade conduction via $A P$ impacts the QRS terminal vector changes; the QRS terminal vector changes indicate the activation download via AP and AV node and is helpful for the diagnosis of preexcitation, especially in patients with latent preexcitation syndrome without delta wave on ECG. 


\section{Abbreviations}

AP: Accessory pathway; AV: Atrioventricular; AVB: Atrioventricular block; ECG: Electrocardiogram

\section{Availability of data and materials}

The datasets used and/or analysed during the current study available from the corresponding author on reasonable request.

\section{Authors' contributions}

All authors fulfill the criteria for authorship. ZLX and RGL conceived and designed the research. ZLX, RGL, QHC, CJL acquired the data, performed statistical analysis, drafted the manuscript and made critical revision of the manuscript for key intellectual content. All authors read and approved the final manuscript.

\section{Ethics approval and consent to participate}

This study was carried out in strict accordance with the recommendations in the Guide for the Care and Use of Laboratory Animals of the National Institutes of Health. The protocol was approved by the Committee on the Ethics of Animal Experiments of the Jinzhou Medical University.

\section{Competing interests}

The authors declare that they have no competing interests.

\section{Publisher's Note}

Springer Nature remains neutral with regard to jurisdictional claims in published maps and institutional affiliations.

\section{Author details}

${ }^{1}$ The Cardiovascular Institute of the First Affiliated Hospital of Jinzhou Medical University, Renmin Street, Jinzhou 121000, Liaoning Province, China. ${ }^{2}$ Department of Respiration Medicine of the First Affiliated Hospital of Jinzhou Medical University, Renmin Street, Jinzhou 121000, Liaoning Province, China.

Received: 12 February 2018 Accepted: 9 May 2018

Published online: 21 May 2018

\section{References}

1. Liu R, Chang Q. Wolff-Parkinson-White syndrome "cured" by myocardial infarction? CMAJ. 2014;186:e297.

2. Eisenberger M, Davidson NC, Todd DM, Garratt CJ, Fitzpatrick AP. A new approach to confirming or excluding ventricular pre-excitation on a 12-lead ECG. Europace. 2010;12:119-23.

3. Gallagher JJ, Smith WM, Kerr CR, Kasell J, Cook L, Reiter M, Sterba R, Harte M. Esophageal pacing: a diagnostic and therapeutic tool. Circulation. 1982; 65:336-41

4. Coumel P, Attuel P. Reciprocating tachycardia in overt and latent preexcitation. Influence of functional bundle branch block on the rate of the tachycardia. Eur J Cardiol. 1974;1:423-36.

5. Kuecherer HF, Kleber Gda S, Melichercik J, Schützendübel R, Beyer T, Brachmann J, Kübler W. Transesophageal echo phase imaging for localizing accessory pathways during adenosine-induced preexcitation in patients with the Wolff-Parkinson-white syndrome. Am J Cardiol. 1996;77:64-71.

6. Liu RG, Chen J. Pre-excitation syndrome with a change in terminal QRS vector. Acta Cardiol. 2013;68:219-21.

7. Liu R, Chen QI, Chen Y, Zhang Y, Xu Z, Wang G. Effects of Antegrade Accessory Pathway Conduction on QRS Terminal Vector in Patients with Preexcitation Syndrome. Pacing Clin Electrophysiol. 2017:40:264-70.

8. Park HE, Chang SA, Kim JH, Oh IY, Choi EK, Oh S. Left ventricular dyssynchrony in pre-excitation syndrome: effect of accessory pathway location and reversibility after ablation therapy. Heart Vessel. 2013;28:199-207.

9. Xu Z, Chang Q, Liu R. GW25-e3149: Preexcitation syndrome:experimential study on the electrocardiogram of antegradely conducting accessory pathway. J Am College Cardiology. 2014;64(Suppl 16):c159.

10. Brembilla-Perrot B, Moejezi RV, Zinzius PY, Jarmouni S, Schwartz J, Beurrier D, Sellal JM, Nossier I, Muresan L, Andronache M, Moisei R, Selton O, Louis $P$, de la Chaise AT. Missing diagnosis of preexcitation syndrome on ECG. Clinical and electrophysiological significance Int J Cardiol. 2013;163:288-93.

11. Kharrat I, Hentati M, Sahnoun M, Krichen S, Trabelsi I, Abid L, Triki F, Mallek S, Kammoun S. Potential danger of ocular compression in paroxysmal supraventricular tachycardia in patients with latent preexcitation. J Electrocardiol. 2009:42:645-7.

12. Garratt CJ, Antoniou A, Griffith MJ, Ward DE, Camm AJ. Use of intravenous adenosine in sinus rhythm as a diagnostic test for latent preexcitation. Am J Cardiol. 1990;65:868-73.

13. Marafioti V, Carbonieri E, Zardini P. Cases in electrocardiography. Am J Emerg Med. 1995;13:649-51.

14. Liu RG, Xu ZL. Further recognition of the ECG of WPW syndrome. Int J Cardiovasc Med. 2008:9:139-42

15. Zhang Y, Liu R, Chen Y. Association of WPW syndrome and first-degree atrioventricular block: electrocardiographic diagnosis. Herz. 2014;39:834-6.

16. Liu R, Chang Q. The diagnosis of myocardial infarction in the WolffParkinson-white syndrome. Int J Cardiol. 2013;167:1083-4.

17. Chang Q, Liu R. Preexcitation syndrome with myocardial infarction complicated by atrioventricular block in both normal and accessory pathway? Am J Emerg Med. 2013;31:1621.e5-7.

18. Chen $Y$, Liu R, Xu Z. Wolff-Parkinson-white syndrome: could a normal PJ interval exclude bundle branch block? Rev Esp Cardiol. 2014;67:153-5.

19. Lau EW, Ng GA, Griffith MJ. A new ECG sign of an accessory pathway in sinus rhythm: pseudo partial right bundle branch block. Heart. 1999;82:244-5.

20. Lim HS, Kuchar D, Subbiah R, Walker B. Secondary $r^{\prime}$ wave in $V(1)$ as a sign of left-sided antegrade accessory pathway conduction. Ann Noninvasive Electrocardiol. 2011;16:407-8

21. Liao Z, Ma J, Hu J, Yang Q, Zhang S. New observation of electrocardiogram during sinus rhythm on the atriofascicular and decremental atrioventricular pathways/clinical perspective: terminal QRS complex slurring or notching. Circ Arrhythm Electrophysiol. 2011;4:897-901.

22. Santulli G, Pagano G, Sardu C, Xie W, Reiken S, D'Ascia SL, Cannone M, Marziliano N, Trimarco B, Guise TA, Lacampagne A, Marks AR. Calcium release channel RyR2 regulates insulin release and glucose homeostasis. J Clin Invest. 2015:125:1968-78.

23. Sardu C, Santamaria M, Paolisso G, Marfella R. microRNA expression changes after atrial fibrillation catheter ablation. Pharmacogenomics. 2015:16:1863-77.

24. Sardu C, Santulli G, Santamaria M, Barbieri M, Sacra C, Paolisso P, D'Amico F, Testa N, Caporaso I, Paolisso G, Marfella R, Rizzo MR. Effects of alpha Lipoic acid on multiple cytokines and biomarkers and recurrence of atrial fibrillation within 1 year of catheter ablation. Am J Cardiol. 2017;119:1382-6.

\section{Ready to submit your research? Choose BMC and benefit from:}

- fast, convenient online submission

- thorough peer review by experienced researchers in your field

- rapid publication on acceptance

- support for research data, including large and complex data types

- gold Open Access which fosters wider collaboration and increased citations

- maximum visibility for your research: over $100 \mathrm{M}$ website views per year

At BMC, research is always in progress.

Learn more biomedcentral.com/submissions 